\title{
Dinâmica de cátions na raiz e folhas de berinjela cultivada sobre doses crescentes de potássio oriundas de duas fontes
}

\author{
Dynamics of cations in the root and leaves of eggplant grown on increasing \\ doses of potassium from two sources \\ Douglas José Marques ${ }^{1 *}$, Fernando Broetto ${ }^{2}$, Ernani Clarete da Silva ${ }^{3}$, Janice Guedes de Carvalho ${ }^{4}$ \\ RESUMO \\ O presente trabalho foi conduzido no Departamento de Produção Vegetal, setor de Horticultura, da UNESP-Campus de Botucatu, \\ SP com o objetivo de avaliar a dinâmica de nutrientes catiônicos na raiz e folha e efeitos na produção de matéria seca da raiz e parte \\ aérea em berinjela cultivada sobre condições de doses crescentes de potássio oriundas de duas fontes distintas $\left(\mathrm{KCl}_{\text {e }} \mathrm{K}_{2} \mathrm{SO}_{4}\right)$. $\mathrm{O}$ \\ experimento foi disposto em delineamento de blocos casualizados, em esquema fatorial $2 \times 4$ (duas fontes de potássio: $\mathrm{KCl}_{\mathrm{e}} \mathrm{K}_{2} \mathrm{SO}_{4}$ \\ e quatro doses de cada fonte equivalente a, 250, 500, 750 e $1000 \mathrm{~kg} \mathrm{ha}^{-1} \mathrm{de} \mathrm{K}_{2} \mathrm{O}$ ) perfazendo oito tratamentos com três repetições. \\ Para a condução do experimento, utilizou-se Latossolo Vermelho distroférrico de textura média (615 g de areia, $45 \mathrm{~g}$ de silte e \\ $340 \mathrm{~g}$ de argila por quilograma de solo). As características avaliadas foram: condutividade elétrica do solo, massa de matéria parte

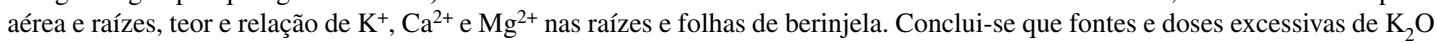 \\ afetaram a produção de massa de matéria seca da raiz e parte aérea assim como a condutividade elétrica. $\mathrm{O}$ acúmulo e a relação de \\ $\mathrm{Ca}^{2+} / \mathrm{K}^{+}, \mathrm{Mg}^{2+} / \mathrm{K}^{+}$foram afetados pelo aumento da concentração de $\mathrm{K}^{+}$e o fertilizante que foi menos prejudicial foi o $\mathrm{K}_{2} \mathrm{SO}_{4}$. \\ Palavras chave: Inibição competitiva, massa de matéria seca, raiz, folha, cátions.
}

\section{ABSTRACT}

This study was conducted at the Department of Plant Production, Sector Horticulture, UNESP - Botucatu, SP, Brazil, in order to assess the dynamics of cationic nutrients in roots and leaves and effects on dry matter production of roots and shoots in eggplant grown on conditions of increasing doses of potassium from two distinct sources $\left(\mathrm{KCl}\right.$ and $\left.\mathrm{K}_{2} \mathrm{SO}_{4}\right)$. The experiment was arranged in randomized blocks in factorial $2 \times 4$ (two sources of potassium, $\mathrm{KCl}$ and $\mathrm{K}_{2} \mathrm{SO}_{4}$ and four doses of each source equivalent, 250, 500, 750 and $1000 \mathrm{~kg} \mathrm{ha}^{-1} \mathrm{~K}_{2} \mathrm{O}$ ) comprising eight treatments with three replicates. For the experiment we used Oxisol medium texture (615 $\mathrm{g}$ of sand, silt $45 \mathrm{~g}$ and $340 \mathrm{~g}$ clay per $\mathrm{kg}$ soil). The characteristics evaluated were: soil electrical conductivity, mass of shoot and root material, content and ratio of $\mathrm{K}^{+}, \mathrm{Ca}^{2+}$ and $\mathrm{Mg}^{2+}$ in roots and leaves of eggplant. We conclude that excessive doses of sources of $\mathrm{K}_{2} \mathrm{O}$ affected the production of dry matter of roots and shoots, as well as electrical conductivity. The accumulation and the relationship of $\mathrm{Ca} 2+/ \mathrm{K}+, \mathrm{Mg}^{2+} / \mathrm{K}^{+}$were affected by increased $\mathrm{K}^{+}$concentration; $\mathrm{K}_{2} \mathrm{SO}_{4}$ was the fertilizer that was less damaging .

Key words: Competitive inhibition, dry matter, root, leaf, cations.

\section{Introdução}

Entre várias hortaliças, a berinjela (Solanum melongena L.) tem sido plantada em condições de cultivo protegido, o qual possibilita um abastecimento contínuo e colheitas em períodos de baixa oferta do produto no mercado, alcançando por isso, preços mais competitivos. Porém, existem muitos problemas relacionados à adubação excessiva, levando o solo a um acúmulo de sais. Knott (1957) alertava para o perigo de se cometer erro fatal para as plantas devido à salinização da zona radicular provocada por esses nutrientes, em especial o K.

Apesar da água utilizada na irrigação nos cultivos protegidos ser de boa qualidade, a adição de fertilizantes, quando se utiliza a técnica de fertirrigação, a

\footnotetext{
Trabalho de dissertação para obtenção do título de mestre em Agronomia-Horticultura do primeiro autor.

1 Departamento de Produção Vegetal-Horticultura, Faculdade de Ciências Agronômicas-UNESP, Caixa Postal 237, 18610-307, Botucatu - SP; douglasjmarques81@yahoo.com.br.

2 Departamento de Química e Bioquímica, IBB-UNESP, Caixa Postal 510, 18618-970, Botucatu - SP; broetto@ibb.unesp.br.

3 Universidade Federal de São João del Rei, Unidade de Sete Lagoas, Caixa Postal 56, 35701-970, Sete Lagoas - MG; clarete@ufsj.edu.br.

4 Departamento de Ciência do Solo, UFLA, Caixa Postal 3037, 37200-000, Lavras, MG; janicegc@ufla.br.

* Autor para correspondência.
} 
torna salina, aumentando o risco de salinização do solo (Blanco et al., 2002). As maiores limitações para o cultivo de berinjela estão relacionadas com a baixa disponibilidade de água e nutrientes no solo durante seu ciclo. A resposta desta espécie vegetal a fatores abióticos tais como salinidade e estresse hídrico, tem sido pouco estudada na cultura da berinjela (Oliveira et al., 2008).

No processo de absorção, as interações catiônicas nos sítios de adsorção e a concentração de íons nutrientes na solução do solo, constituem aspectos de importância na nutrição das plantas e produção das culturas (Khasawneh, 1971). A taxa de absorção de um nutriente pela planta depende dos cátions dissolvidos na solução de solo em equilíbrio dinâmico com os cátions do complexo de troca (Bull, 1986). A absorção de um nutriente é afetada também pela natureza dos cátions complementares, isto é, há influência de um íon adsorvido sobre a liberação de um outro, para a solução do solo, a partir da superfície trocadora, além das relações que envolvem os cátions no solo (Tisdale et al., 1985).

$\mathrm{Na}$ avaliação da capacidade potencial de fertilidade dos solos, devem ser ajustadas as relações entre cátions para a cultura, em vista das interações competitivas entre diferentes íons nutrientes que influem na disponibilidade e possibilidade de absorção da célula através da membrana (Epstein, 1975).

Em virtude da condição de salinização do solo, podem ocorrer desordens nutricionais, induzindo relações antagônicas entre nutrientes na planta, o que reduz significativamente os rendimentos das culturas (Grattans e Grieve, 1993). A elevação do teor de K no solo pode induzir desequilíbrio nutricional para as plantas (Hagin e Tucker, 1982). Essas interações também podem ocorrer entre os nutrientes na solução do solo, afetando a disponibilidade, quais sejam: antagonismo, inibição competitiva e inibição não competitiva, além de sinergismo (Malavolta, 1987), o que pode causar uma dinâmica diferenciada entre cátions nas folhas e raízes das plantas. No entanto, pouco se conhece sobre as interações entre cátions causadas por doses em excesso de $\mathrm{K}_{2} \mathrm{O}$ induzidas por diferentes fontes $\left(\mathrm{KCl} \mathrm{e} \mathrm{K}_{2} \mathrm{SO}_{4}\right)$. O principal uso do cloreto de potássio é como fertilizante na agricultura sendo a principal fonte de utilização o cloreto de potássio seguido do sulfato de potássio em menor escala. $\mathrm{O}$ sulfato de potássio tem um efeito menos salino que o cloreto de potássio. Seu índice salino por unidade de $\mathrm{K}_{2} \mathrm{O}$ é a metade do índice do cloreto de potássio, o que o torna mais indicado para solos com tendência à salinização (Nogueira et al., 2001).
Sendo assim, objetivou-se estudar a dinâmica de nutrientes catiônicos nas folhas e raízes e os efeitos na produção de matéria seca da parte aérea em berinjela cultivada sobre condições de salinidade.

\section{Material e Métodos}

O experimento foi realizado nas dependências do Departamento de Produção Vegetal-HorticulturaUNESP, Campus de Botucatu, São Paulo. O clima de Botucatu é classificado como Cwa, segundo a classificação internacional de Koppen (Cunha e Martins, 2009), que significa clima temperado quente, com chuvas no verão e seca no inverno, temperatura média do mês mais frio inferior a $17^{\circ} \mathrm{C}$ e do mês quente superior a $23{ }^{\circ} \mathrm{C}$, apresentando como coordenadas geográficas $22^{\circ} 51^{\prime}$ de latitude sul, $48^{\circ} 26^{\prime}$ de longitude oeste e altitude de $815 \mathrm{~m}$. Utilizou-se a cultivar de berinjela denominada de Embu. O experimento foi disposto em delineamento de blocos casualizados, em esquema fatorial $2 \times 4$ (duas fontes de potássio: $\mathrm{KCl}$ e $\mathrm{K}_{2} \mathrm{SO}_{4}$ e quatro doses crescentes de cada fonte equivalente a 250 , 500,750 e $1000 \mathrm{~kg} \mathrm{ha}^{-1}$ de $\mathrm{K}_{2} \mathrm{O}$ ) perfazendo oito tratamentos com cinco repetições para a avaliação da condutividade elétrica do solo e três repetições para as demais características avaliadas. As doses crescentes de $\mathrm{K}_{2} \mathrm{O}$ foram indicadas com base nas recomendações do Boletim 100 (Raij et al. 1996) para a cultura da berinjela cujos tratamentos e equivalência em vasos estão descritos na Tabela 1. A equivalência por vasos foi calculada com base no teor percentual de $\mathrm{K}_{2} \mathrm{O}$ de cada fonte considerando-se $58 \%$ para a fonte $\mathrm{KCl}$ e $44 \%$ para a fonte $\mathrm{K}_{2} \mathrm{SO}_{4}$. Para a condução do experimento, utilizou-se Latossolo Vermelho Distroférrico (Embrapa, 1997) de textura média (615 g de areia, $45 \mathrm{~g}$ de silte e $340 \mathrm{~g}$ de argila por quilograma de solo), coletado na gleba "Patrulha" da FCA-UNESP, a uma profundidade de 0 a $20 \mathrm{~cm}$ para a análise química. O solo apresentava inicialmente as seguintes características: $\mathrm{pH}(4,1)$, matéria orgânica $\left(17 \mathrm{~g} \mathrm{dm}^{3}\right)$, fósforo $\left(2 \mathrm{mg} \mathrm{dm}^{3}\right.$ resina $)$, potássio $(0,2$ $\left.\mathrm{mmol}_{\mathrm{c}} \mathrm{dm}^{-3}\right)$, cálcio $\left(2 \mathrm{mmol}_{\mathrm{c}} \mathrm{dm}^{-3}\right)$ e magnésio $\left(1 \mathrm{mmol}_{\mathrm{c}} \mathrm{dm}^{-3}\right)$. O solo passou em peneira de 5 $\mathrm{mm}$ sendo acondicionados em vasos plásticos com capacidade para $32 \mathrm{~L}$ de solo. Os vasos apresentavam furos no fundo onde foi colocada uma camada de sombrite dobrada de 0,30 m para evitar perda de solo e para permitir a drenagem do excesso de água caso ocorresse. Os cálculos para a correção do solo seguiram recomendações de Raij 
Tabela 1. Tratamentos e equivalência em vasos com base nas duas fontes de $\mathrm{K}_{2} 0, \mathrm{KCl}$ e $\mathrm{K}_{2} \mathrm{SO}_{4}$.

\begin{tabular}{|c|c|c|c|c|}
\hline \multirow{2}{*}{ Tratamento } & \multicolumn{2}{|c|}{ Fonte do Nutriente } & \multicolumn{2}{|c|}{ Equivalência em Vasos (g) } \\
\hline & $\mathrm{KCl}$ & $\mathrm{K}_{2} \mathrm{SO}_{4}$ & $\mathrm{KCl}$ & $\mathrm{K}_{2} \mathrm{SO}_{4}$ \\
\hline $\mathrm{T} 1$ & $250 \mathrm{~kg} \mathrm{ha}^{-1}$ de $\mathrm{K}_{2} \mathrm{O}$ & & 6,81 & \\
\hline $\mathrm{T} 2$ & $500 \mathrm{~kg} \mathrm{ha}^{-1}$ de $\mathrm{K}_{2} \mathrm{O}$ & & 13,63 & \\
\hline $\mathrm{T} 3$ & $750 \mathrm{~kg} \mathrm{ha}^{-1}$ de $\mathrm{K}_{2} \mathrm{O}$ & & 20,44 & \\
\hline $\mathrm{T} 4$ & 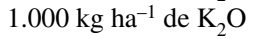 & & 27,26 & \\
\hline T5 & & $250 \mathrm{~kg} \mathrm{ha}^{-1}$ de $\mathrm{K}_{2} \mathrm{O}$ & & 8,31 \\
\hline T6 & & $500 \mathrm{~kg} \mathrm{ha}^{-1}$ de $\mathrm{K}_{2} \mathrm{O}$ & & 16,76 \\
\hline $\mathrm{T} 7$ & & $750 \mathrm{~kg} \mathrm{ha}^{-1}$ de $\mathrm{K}_{2} \mathrm{O}$ & & 25,14 \\
\hline $\mathrm{T} 8$ & & $1.000 \mathrm{~kg} \mathrm{ha}^{-1}$ de $\mathrm{K}_{2} \mathrm{O}$ & & 33,52 \\
\hline
\end{tabular}

et al., (1996), visando à elevação da saturação por bases a $80 \%$, sendo necessário aplicar $6.000 \mathrm{t} \mathrm{ha}^{-1}$, equivalente a $96 \mathrm{~g}$ de calcário dolomítico (PRNT = $91 \%$ ) por vaso. A adubação básica para nitrogênio e fósforo foi baseada nas recomendações de Raij et al., (1996) para a cultura da berinjela, para o $\mathrm{N}$ aplicou-se o equivalente a 3,2 $\mathrm{g}$ por vaso, na forma de sulfato de amônio. Para o P, utilizou-se 28,2 g de termofosfato máster por vaso. Utilizou-se metade da recomendação para adubação orgânica adicionando-se $10 \mathrm{t} \mathrm{ha}^{-1}$ de esterco de curral curtido, equivalente a $160 \mathrm{~g}$ por vaso. As adubações de cobertura tiveram início aos 15 dias após transplante (DAT), sendo realizadas quinzenalmente. A fonte de $\mathrm{N}$ usada na cobertura foi o nitrato de cálcio com a dose de (22,82 g por vaso) dividida em 14 aplicações. A adubação básica para o $\mathrm{K}$ foi feita a partir de duas fontes, cloreto e sulfato de potássio, conforme descrito na Tabela 1. Após a aplicação dos adubos, o solo foi umedecido durante 35 dias, necessária a reação química do corretivo e fertilizante. As mudas de berinjela foram produzidas em bandejas com 128 células com 6,0 a $6,2 \mathrm{~cm}$ de altura, com substrato composto por material inerte e livre de patógenos. O transplantio foi realizado no dia 22 de outubro de 2007 com uma muda por vaso, quando as mesmas apresentavam três a quatro folhas definitivas, o que ocorreu por volta dos 35 dias após a semeadura. Os vasos foram distribuídos com espaçamento de $0,63 \mathrm{~m}$ entre plantas e 1,0 m entre linhas. Os tensiômetros foram instalados no ponto médio do vaso a uma profundidade efetiva do sistema radicular 0,20 m, 0,30 m distância vertical da superfície do mercúrio na cuba até a superfície do solo $(\mathrm{cm})$ e $0,15 \mathrm{~m}$ de distancia do colo da planta. A irrigação foi realizada manualmente para elevar à umidade do solo a capacidade de campo, a qual corresponde um potencial mátrico de aproximadamente $-30 \mathrm{KPa}$.
Durante o experimento, coletaram-se alíquotas de solução do solo, em intervalos de 7 dias. A solução foi coletada com auxilio de um extrator de solo instalado no ponto médio da profundidade efetiva do sistema radicular $0,15 \mathrm{~m}$ e $0,10 \mathrm{~m}$ de distancia do caule da planta. Para a determinação da C.E., utilizou-se condutivímetro digital (Lutron, mod. CD-4303). As leituras da C.E. foram corrigidas com base na umidade do solo.

A raiz e (folhas+caule) foram coletadas aos 50 e 120 dias após o transplantio (DAT), para a determinação massa secas da parte aérea (MMSPA). Os componentes foram secos em estufa a $70{ }^{\circ} \mathrm{C}$, com ventilação forçada, até atingirem massa constante. As raízes foram separadas da parte aérea através de um corte no colo da planta, lavadas com água deionizada para retirar o excesso de solo aderido às raízes. A parte aérea+caule foi processada em conjunto. A análise química da raiz e folha foi conduzida conforme metodologia descrita por Malavolta et al. (1997), no laboratório de análise foliar do Departamento de Recursos Naturais-Ciência do Solo, FCA-UNESP-Campus de Botucatu, SP.

Os dados foram submetidos à análise de variância (teste F), aplicando-se o teste de regressão polinomial de segunda ordem, para os casos em que ocorreu efeito significativo, conforme recomenda Ferreira (1999).

\section{Resultados e Discussão}

Para todas as características avaliadas observouse interação significativa entre os fatores (Tabelas 2 , 3 e 4). A condutividade elétrica aumentou linearmente na medida em que se aumentaram as doses de $\mathrm{K}_{2} \mathrm{O}$ independente da fonte utilizada (Figura 1). Entretanto, observou-se que os valores de condutividade elétrica foram significativa superiores com 
o uso das doses de $\mathrm{K}_{2} \mathrm{O}(\mathrm{KCl})$ indicando maior aumento da salinidade do solo. Aos 50 DAT houve um decréscimo linear da massa de matéria seca da parte aérea (MMSPA) com o aumento das doses de $\mathrm{K}_{2} \mathrm{O}\left(\mathrm{K}_{2} \mathrm{SO}_{4}\right)$ sendo que o contrário foi encontrado

Tabela 2. Quadrados Médio (QM) e Significância para a característica Condutividade Elétrica em solos cultivado com berinjela e sob doses de potássio.

\begin{tabular}{lcc}
\hline \multirow{2}{*}{ Fonte de Variação } & GL & QM \\
\cline { 3 - 3 } & & Condutividade Elétrica \\
\hline Blocos & 4 & \\
Fontes de Potássio (A) & 1 & $9,157^{*}$ \\
Doses de $\mathrm{K}_{2} \mathrm{O}(\mathrm{B})$ & 3 & $12,506^{*}$ \\
$\mathrm{~A} \times \mathrm{B}$ & 3 & $1,44^{*}$ \\
Resíduo & 28 & \\
Total & 39 & 29,41 \\
CV\% & & \\
\hline
\end{tabular}

* Significativo ao nível de 5\%. com o aumento das doses de $\mathrm{K}_{2} \mathrm{O}$ (KCl) (Figura 2A). Provavelmente aos 50 DAT em termos de doses de $\mathrm{K}_{2} \mathrm{O}(\mathrm{KCl})$ a planta não tenha atingido o máximo de produção de MMSPA. Aos 120 DAT a produção de MMSPA aumentou com as doses $\mathrm{K}_{2} \mathrm{O}\left(\mathrm{K}_{2} \mathrm{SO}_{4}\right)$ até a um máximo $598,5 \mathrm{~kg} \mathrm{ha}^{-1} \mathrm{de} \mathrm{K}_{2} \mathrm{O}$ o mesmo acontecendo até ao valor 711,5 $\mathrm{kg} \mathrm{ha}^{-1}$ quando a fonte de $\mathrm{K}_{2} \mathrm{O}$ foi $\mathrm{KCl}$ quando iniciou-se decréscimo na produção de matéria seca. Estes resultados indicam uma provável resposta de estresse da planta ao aumento da salinidade do solo causado por uma dose maior do fertilizante potássico. Marques et al. (2010) encontraram resultados semelhantes quando analisaram produção de matéria seca da raiz em berinjela conduzida em solos com estresse salino induzido por excesso de sais de potássio no solo. Estes resultados podem ser explicados pela diferença de efeito de salinidade entre as duas fontes de $\mathrm{K}_{2} \mathrm{O}$ sendo que a fonte $\left(\mathrm{K}_{2} \mathrm{SO}_{4}\right)$ com menor efeito. Como todos os fertilizantes, o $\mathrm{K}$ em qualquer

Tabela 3. Quadrados Médios (QM) e Significância para as características avaliadas: Massa de Matéria Seca da Parte Aérea aos 50 Dias Após Transplantio (MMSPA 50 DAT), Massa de Matéria Seca da Parte Aérea aos 120 Dias Após Transplantio (MMSPA 120 DAT), teor de K, Ca e Mg na folha de berinjela.

\begin{tabular}{|c|c|c|c|c|c|c|}
\hline \multirow[b]{2}{*}{ Fonte de Variação } & \multirow[b]{2}{*}{ GL } & \multicolumn{5}{|c|}{ QM } \\
\hline & & $\begin{array}{l}\text { MMSPA } \\
\text { (50 DAT) }\end{array}$ & $\begin{array}{c}\text { MMSPA } \\
\text { (120 DAT) }\end{array}$ & $\begin{array}{l}\text { Teor K } \\
\text { (Folha) }\end{array}$ & $\begin{array}{l}\text { Teor Ca } \\
\text { (Folha) }\end{array}$ & $\begin{array}{c}\text { Teor Mg } \\
\text { (Folha) }\end{array}$ \\
\hline Blocos & 2 & & & & & \\
\hline Fontes Potássio (A) & 1 & $7954,29 *$ & $6343,00 *$ & $504,16^{*}$ & $130,66^{*}$ & $3,76^{*}$ \\
\hline Doses de $\mathrm{K}_{2} \mathrm{O}(\mathrm{B})$ & 3 & $100,06^{*}$ & $1808,00 *$ & $52,94 *$ & $77,77 *$ & $5,55^{*}$ \\
\hline $\mathrm{A} \times \mathrm{B}$ & 3 & $202,62 *$ & $854,00^{*}$ & $104,50 *$ & $4,88 *$ & $2,26^{*}$ \\
\hline Resíduo & 14 & & & & & \\
\hline Total & 23 & & & & & \\
\hline $\mathrm{CV}(\%)$ & & 1,09 & 4,0 & 2,62 & 6,65 & 5,34 \\
\hline
\end{tabular}

* Significativo ao nível de $5 \%$.

Tabela 4. Quadrados médios (QM) e significância para as características avaliadas: massa de matéria seca da raiz aos 50 Dias Após Transplantio (MMSR 50 DAT), Massa de Matéria Seca da Raiz aos 120 Dias Após Transplantio (MMSR 120 DAT), Teor de K, Ca e Mg na raiz de berinjela.

\begin{tabular}{|c|c|c|c|c|c|c|}
\hline \multirow[b]{2}{*}{ FV } & \multirow[b]{2}{*}{ GL } & \multicolumn{5}{|c|}{ QM } \\
\hline & & $\begin{array}{c}\text { MMSR } \\
(50 \text { DAT) }\end{array}$ & $\begin{array}{c}\text { MMSR } \\
(120 \text { DAT) }\end{array}$ & $\begin{array}{l}\text { Teor K } \\
\text { (Raiz) }\end{array}$ & $\begin{array}{c}\text { Teor Ca } \\
\text { (Raiz) }\end{array}$ & $\begin{array}{c}\text { Teor Mg } \\
\text { (Raiz) }\end{array}$ \\
\hline Blocos & 2 & & & & & \\
\hline Fontes Potássio (A) & 1 & $100,98 *$ & $15368,00^{*}$ & $337,80^{*}$ & $20,16^{*}$ & $0,32 *$ \\
\hline Doses de $\mathrm{K}_{2} \mathrm{O}(\mathrm{B})$ & 3 & $2,91 *$ & $4939,00^{*}$ & $17,00 *$ & $6,55^{*}$ & $1,47^{*}$ \\
\hline $\mathrm{A} \times \mathrm{B}$ & 3 & $20,99 *$ & $4648,00^{*}$ & $150,50 *$ & $6,05^{*}$ & $0,0004 *$ \\
\hline Resíduo & 14 & & & & & \\
\hline Total & 23 & & & & & \\
\hline $\mathrm{CV}(\%)$ & & 5,82 & 5,82 & 12,38 & 5,53 & 2,08 \\
\hline
\end{tabular}

* Significativo ao nível de 5\%. 


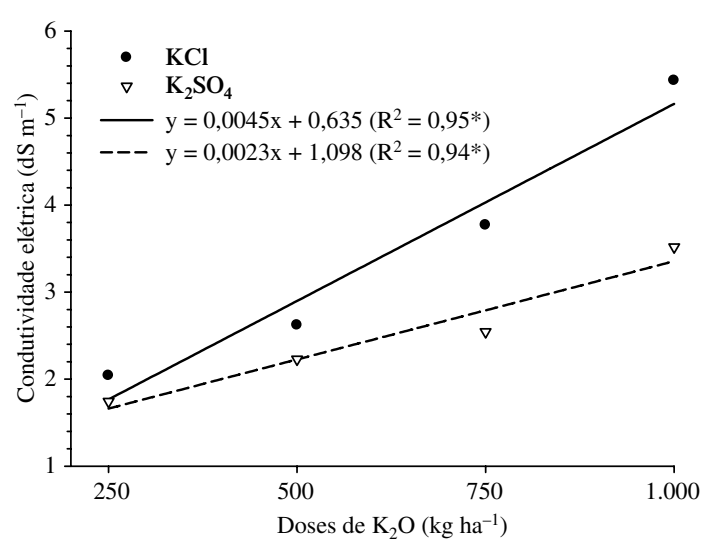

Figura 1. Valor médio da condutividade elétrica do solo (dS $\mathrm{m}^{-1}$ ) coletado através de extrator de solução do solo, em função de fontes e doses de potássio, durante o desenvolvimento da cultura da berinjela.

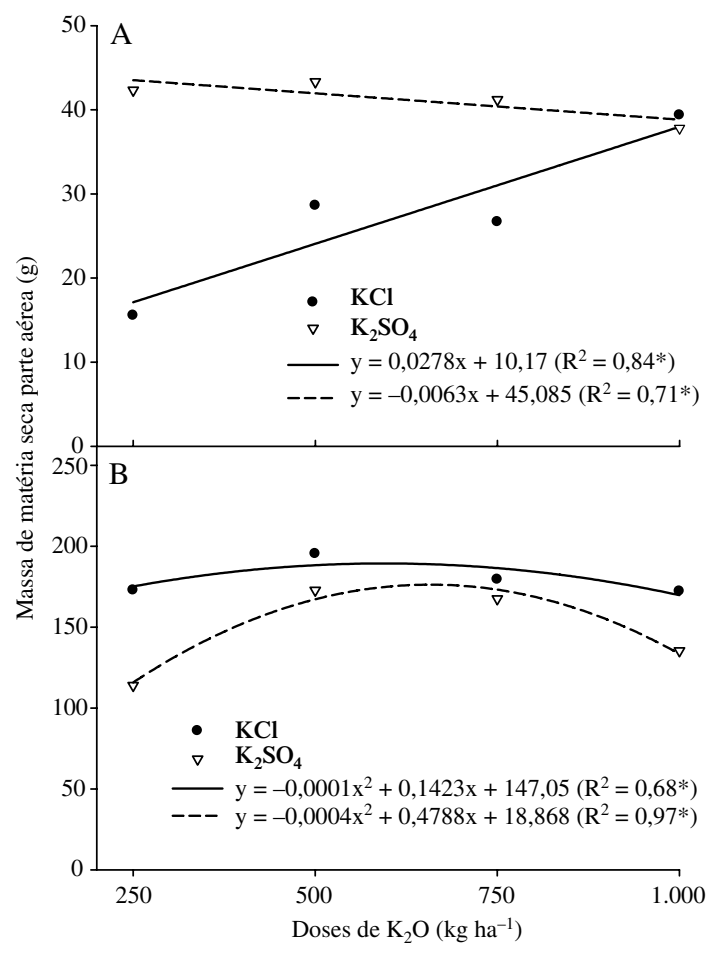

Figura 2. Média da massa de matéria seca das folhas+caule (MMSPA) coletada aos 50 DAT (Figura A) e 120 DAT (Figura $\mathrm{B}$ ) em função de fontes de potássio $\left(\mathrm{KCl}\right.$ e $\left.\mathrm{K}_{2} \mathrm{SO}_{4}\right)$ e doses de potássio.

forma que se apresente, aumenta o teor de sal na solução do solo. Enquanto a condutividade elétrica de soluções equimolares de vários sais de potássio aumenta na ordem $\mathrm{KH}_{2} \mathrm{PO}_{4}<\mathrm{KNO}_{3}<\mathrm{KCl}<\mathrm{K}_{2} \mathrm{SO}_{4}$, a tolerância das plantas à salinidade cai na ordem
$\mathrm{KH}_{2} \mathrm{PO}_{4}>\mathrm{K}_{2} \mathrm{SO}_{4}>\mathrm{KCl}>\mathrm{KNO}_{3}$, observando que o $\mathrm{K}_{2} \mathrm{SO}_{4}$ é a exceção à regra de que a sensibilidade das plantas aos sais aumenta com a condutividade elétrica (Nogueira et al., 2001). Segundo Silva et al. (2001) a salinidade do solo provocada por dose excessiva de $\mathrm{KCl}$ reduziu o crescimento das raízes e da parte aérea em plantas de pimentão diminuindo, consequientemente, a absorção e o acúmulo de nutrientes. Aragão et al. (2009) concluíram que o estresse salino produziu efeito negativo para todas as características avaliadas em melão. Estes resultados corroboram os resultados encontrados por Souza et al. (2007), que descreveu o efeito negativo imediato da salinidade do solo sobre a produção da massa seca da parte aérea (caule e folhas) e da parte radicular em Physalis angulata da mesma família da berinjela.

Para teor de cátions nas raízes das plantas de berinjela (Figuras 3A, B, C) houve comportamentos distintos. Em termos de acúmulo de $\mathrm{K}^{+}$(Figura $3 \mathrm{~A}$ ) houve um ajuste quadrático para as doses de $\mathrm{K}_{2} \mathrm{O}$ $(\mathrm{KCl})$ e linear $\mathrm{K}_{2} \mathrm{O}\left(\mathrm{K}_{2} \mathrm{SO}_{4}\right)$ observando-se que nas menores doses o acúmulo foi significativamente menor quando utilizou-se a fonte $\mathrm{K}_{2} \mathrm{SO}_{4}$. $\mathrm{O}$ ajuste linear mostra comportamento bem diferente de $\mathrm{K}^{+}$ que aumentou na medida em que se aumentaram as doses de $\mathrm{K}_{2} \mathrm{O}$. Para acúmulo de $\mathrm{Ca}^{2+}$ nas raízes (Figura 3B) houve ajuste linear para a fonte $\mathrm{K}_{2} \mathrm{SO}_{4}$ e quadrático para a fonte $\mathrm{KCl}$. Em termos de acúmulo de $\mathrm{Mg}^{2+}$ (Figura 3C), houve um ajuste linear considerando a fonte $\mathrm{K}_{2} \mathrm{SO}_{4}$ com decréscimo no teor na medida do aumento das doses até a um teor inferior ao acúmulo provocado pela fonte $\mathrm{KCl}$, na maior dose do fertilizante, configurando interação significativa entre os fatores. Em termos gerais, com exceção do cátion $\mathrm{Mg}^{2+} \mathrm{o}$ acúmulo de $\mathrm{K}^{+}$e $\mathrm{Ca}^{2+}$ foram sempre maiores nas menores doses quando foi usada a fonte $\mathrm{KCl}$, tendendo a se igualar nas maiores doses.

Os dados de massa de matéria seca da raiz aferidos aos 50 e 120 DAT (Figuras 4A e 4B) revelaram comportamentos distintos entre as duas fontes. Aos 50 DAT (Figura 4A) observou-se interação significativa entre os fatores onde nas menores doses a massa de matéria seca foi significativamente superior quando usado a fonte $\mathrm{K}_{2} \mathrm{SO}_{4}$. Por outro lado, a ajuste linear crescente para a fonte $\mathrm{KCl}$ e decrescente para a fonte $\mathrm{K}_{2} \mathrm{SO}_{4}$ permitiu teor estatisticamente igual nas maiores doses.

Os dados observados aos 120 DAT (Figura 4B) registraram aumento no valor de massa de matéria 


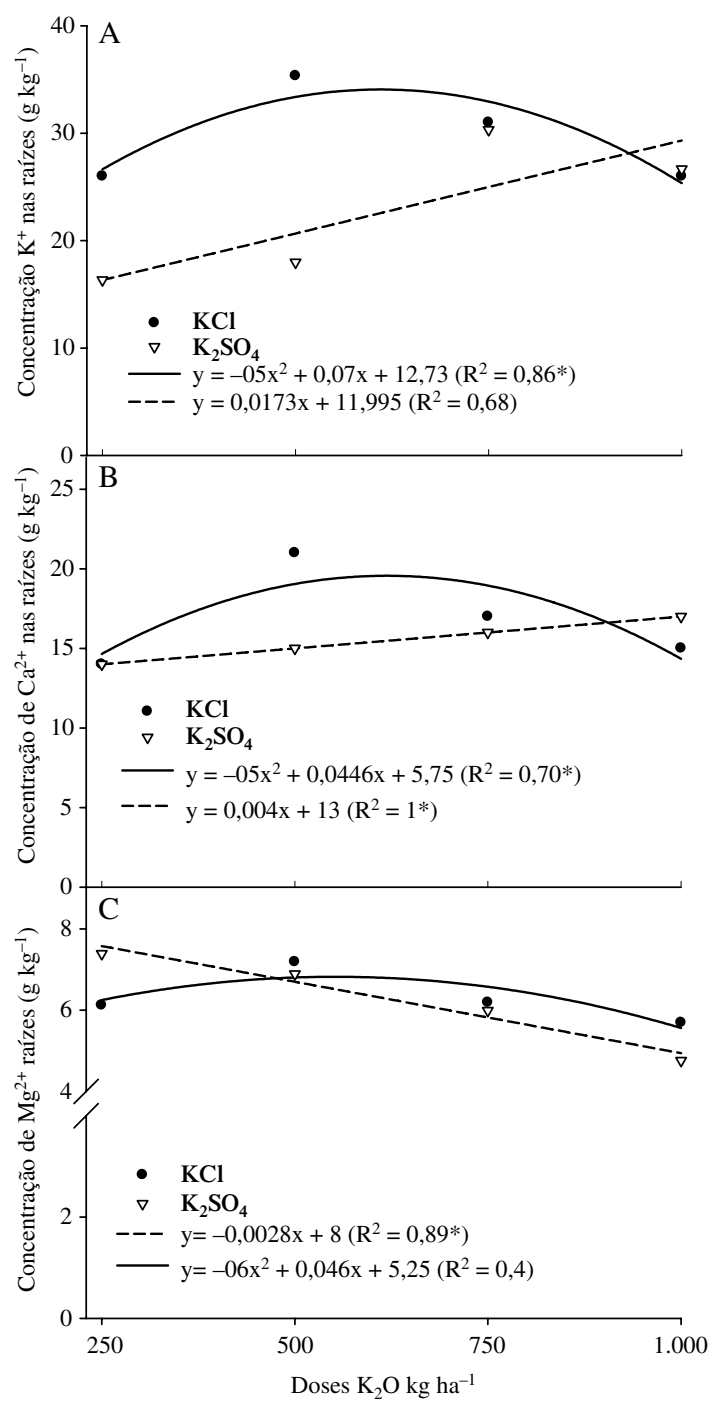

Figura 3. Concentração de $\mathrm{K}^{+}$(Figura A), $\mathrm{Ca}^{2+}$ (Figura B), $\mathrm{Mg}^{+}$ (Figura $\mathrm{C}$ ) nas raízes das plantas de berinjela durante o período experimental em função de fontes de potássio $\left(\mathrm{KCl}\right.$ e $\left.\mathrm{K}_{2} \mathrm{SO}_{4}\right)$ e doses de potássio.

seca da raiz provavelmente em função do maior tempo de absorção de nutrientes. Entretanto, observa-se significativamente o maior valor nas menores doses de $\mathrm{K}_{2} \mathrm{O}(\mathrm{KCl})$ o que pode ser explicado pela maior facilidade de absorção de $\mathrm{K}_{2} \mathrm{O}(\mathrm{KCl})$ pelas plantas. Por outro lado, observou-se redução linear da massa de matéria seca da raiz na medida em que as doses de $\mathrm{K}_{2} \mathrm{O}(\mathrm{KCl})$ foram aumentadas diferindo do aumento das doses de $\mathrm{K}_{2} \mathrm{O}\left(\mathrm{K}_{2} \mathrm{SO}_{4}\right)$ que registrou comportamento quadrático (Figura 4B). A grande concentração de íons no solo, principalmente $\mathrm{Na}^{+}$ $\mathrm{e} \mathrm{Cl}^{-}$, pode causar a desequilíbrio na homeostase do

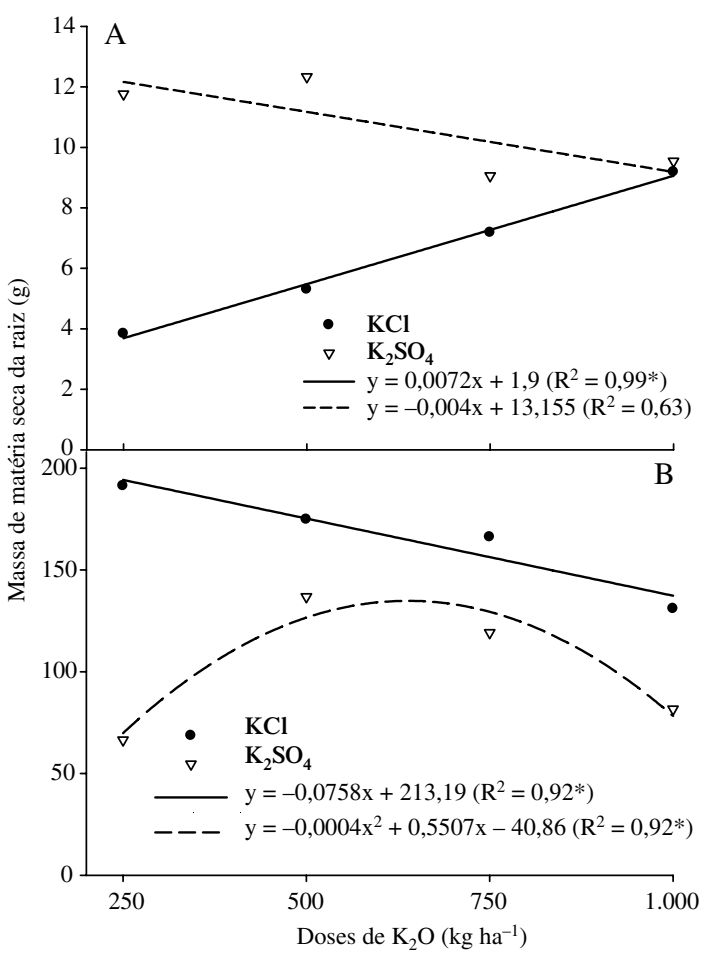

Figura 4. Média da massa de matéria seca das raízes (MMSR) de berinjela em função de fontes de potássio $\left(\mathrm{KCl}\right.$ e $\left.\mathrm{K}_{2} \mathrm{SO}_{4}\right)$ e doses de potássio coletados aos 50 DAT (Figura A) e 120 DAT (Figura B).

potencial de água e desbalanço iônico na interface solo-planta e promover toxicidade no vegetal, afetando o seu crescimento e a produção de fitomassa (Asch et al., 2000), em conseqüência da redução da absorção de nutrientes minerais, como o potássio, cálcio e manganês (Lutts et al., 1999).

Para o teor de $\mathrm{K}^{+}$nas folhas verificou-se incremento superior para a fonte $\mathrm{KCl}$ quando comparado com a fonte $\mathrm{K}_{2} \mathrm{SO}_{4}$ (Figura 5A). No entanto, em se tratando da fonte $\mathrm{K}_{2} \mathrm{SO}_{4}$, o teor $\mathrm{K}^{+}$aumentou em função das doses de $\mathrm{K}_{2} \mathrm{O}$. Já para o fertilizante $\mathrm{KCl}$ não foi possível definir uma tendência definida de aumento ou decréscimo no teor de $\mathrm{K}^{+}$nas folhas de berinjela.

Observou-se que o teor de $\mathrm{Ca}^{2+}$ nas folhas de berinjela foi superior para fonte $\mathrm{K}_{2} \mathrm{SO}_{4}$ quando comparado com a fonte $\mathrm{KCl}$ (Figura $5 \mathrm{~B}$ ). Contudo notou-se que para a fonte $\mathrm{K}_{2} \mathrm{SO}_{4}$ houve decréscimo no teor de $\mathrm{Ca}^{2+}$ nas folhas em função do aumento das doses de $\mathrm{K}_{2} \mathrm{O}$. Já para o fertilizante $\mathrm{KCl}$ não foi possível definir decréscimo ou incremento de $\mathrm{Ca}^{2+}$. Estes dados sugerem que o estresse salino induzido pela fonte $\mathrm{KCl}$ não foi suficiente para afetar o teor 


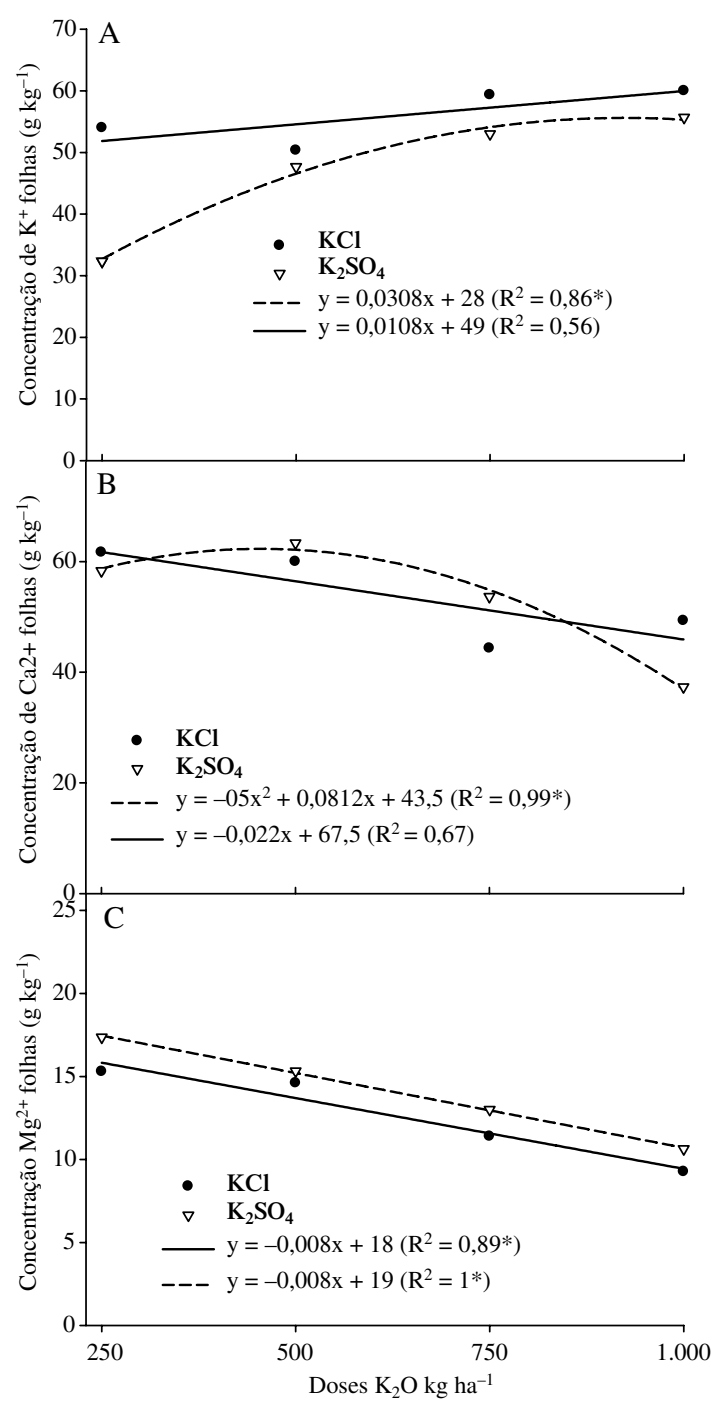

Figura 5. Concentração de $\mathrm{K}^{+}$(Figura A), $\mathrm{Ca}^{2+}$ (Figura B), $\mathrm{Mg}^{+}$ (Figura $\mathrm{C}$ ) nas folhas das plantas de berinjela durante o período experimental em função fontes de potássio $\left(\mathrm{KCl}\right.$ e $\left.\mathrm{K}_{2} \mathrm{SO}_{4}\right)$ e doses de potássio.

de $\mathrm{Ca}^{2+}$ nas folhas. Em termos de teor de $\mathrm{Mg}^{2+}$ nas folhas houve diferenças significativas em função das fontes sendo que a fonte $\mathrm{K}_{2} \mathrm{SO}_{4}$ proporcionou maior teor desse nutriente (Figura 5C). Também foi possível notar que o aumento da salinidade do solo induzida pelas doses de $\mathrm{K}_{2} \mathrm{O}$ favoreceu resposta mais acentuada do teor de $\mathrm{Mg}^{2+}$ nas folhas. Estes resultados são concordantes com Hagin e Tucker (1982) que demonstraram que a elevação do teor de $\mathrm{K}^{+}$no solo pode induzir desequilíbrio nutricional para as plantas. No presente experimento, a alta concentração de $\mathrm{K}_{2} \mathrm{O}$ na solução do solo pode ter

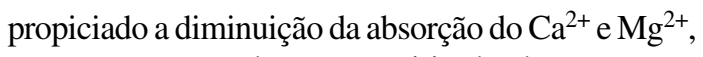
que competem pelo mesmo sitio de absorção.

As relações $\left(\mathrm{Ca}^{2+} / \mathrm{K}_{2} \mathrm{O}\right.$ e $\left.\mathrm{Mg}^{2+} / \mathrm{K}_{2} \mathrm{O}\right)$ revelaram importantes variáveis quando o objetivo foi avaliar o estresse mineral e seu efeito sobre a inibição competitiva de cátions. $\mathrm{O}$ incremento na salinidade do solo induzido pela duas diferentes fontes de potássio aplicadas no solo $\left(\mathrm{KCl}_{\mathrm{e}} \mathrm{K}_{2} \mathrm{SO}_{4}\right)$ afetou as relações $\mathrm{Ca}^{2+} / \mathrm{K}_{2} \mathrm{O}$ e $\mathrm{Mg}^{2+} / \mathrm{K}_{2} \mathrm{O}$ nas raízes (Figuras $6 \mathrm{~A}$ e 6B). Em se tratando de teor de $\mathrm{Ca}^{2+}$ e com relação à fonte $\mathrm{KCl}$ o aumento das doses de $\mathrm{K}_{2} \mathrm{O}$ provocou comportamento quadrático com tendência de redução na relação $\mathrm{Ca} / \mathrm{Mg}$ a partir das maiores doses (Figura 6A). Entretanto para a fonte $\mathrm{K}_{2} \mathrm{SO}_{4}$, verificou-se que provavelmente o menor poder salino da fonte não interferiu no teor de $\mathrm{Ca}^{2+}$ sendo este registrando aumento da relação com o aumento das doses do fertilizante (Figura 6A). Para a relação $\mathrm{Mg}^{2+}$ / $\mathrm{K}_{2} \mathrm{O}$ com referência ao tratamento $\mathrm{K}_{2} \mathrm{O}(\mathrm{KCl})$ não foi possível verificar resultados consistentes através da equação para o efeito do estresse de $\mathrm{K}_{2} \mathrm{O}$ (Figura 6B). No entanto para a fonte $\mathrm{K}_{2} \mathrm{SO}_{4}$, verificou-se que com o aumento das doses de $\mathrm{K}_{2} \mathrm{O}$, diminui o teor de

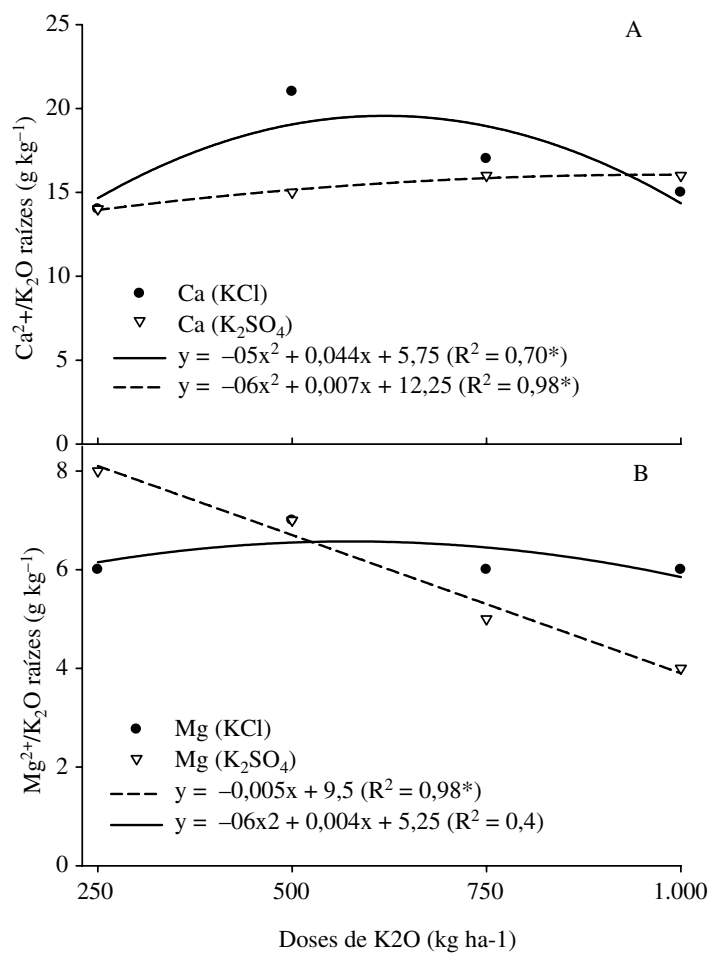

Figura 6. Relação média do teor de cálcio/potássio (Figura A) e magnésio/potássio (Figura B) nas raízes de plantas de berinjela em função de fontes de potássio $\left(\mathrm{KCl} \mathrm{e} \mathrm{K}_{2} \mathrm{SO}_{4}\right)$ e doses de potássio. 
$\mathrm{Mg}^{2+}$ nas raízes de plantas de berinjela (Figura 5B). Trabalhos com sorgo têm reportado que as concentrações de magnésio podem permanecer constantes na parte aérea (Azevedo Neto et al., 2004) ou diminuir na parte aérea e nas raízes (Kawasaki et al., 1983) com o incremento do estresse salino.

A relação média do teor de cálcio/potássio (Figura 7A) e magnésio/potássio (Figura 7B) em folhas de plantas de berinjela foram altamente significativas. A relação $\mathrm{Ca}^{2+} / \mathrm{K}^{+} \mathrm{e} \mathrm{Mg}^{2+} / \mathrm{K}^{+}$foi afetada pelas doses excesso de $\mathrm{KCl}$ e $\mathrm{K}_{2} \mathrm{SO}_{4}$. No presente experimento, a alta concentração de $\mathrm{K}_{2} \mathrm{O}$ na solução do solo pode ter induzida a menor absorção $\mathrm{Ca}^{+2} \mathrm{e}$ $\mathrm{Mg}^{2+}$ (Figuras 7A e 7B). Malavolta (1980), explica que existem na literatura muitos relatos sobre o antagonismo entre macronutrientes catiônicos $\left(\mathrm{K}^{+} / \mathrm{Ca}^{2+}\right)$ $\mathrm{Mg}^{2+}$ ) explicando que o aumento na concentração de um elemento pode diminuir a absorção do outro. Os resultados encontrados neste trabalho relacio-

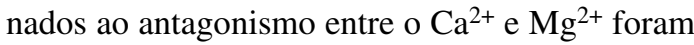
em função do aumento das doses de $\mathrm{K}_{2} \mathrm{O}$ induzidas por diferentes fontes potássicas $\left(\mathrm{KCl}\right.$ e $\left.\mathrm{K}_{2} \mathrm{SO}_{4}\right)$.

\section{Conclusões}

A fonte sulfato de potássio, pode ser mais antagônica que a fonte $\mathrm{KCl}$ competindo de forma mais direta com o $\mathrm{Mg}^{2+}$ nas raízes das plantas de berinjela.

As doses em excesso de $\mathrm{K}_{2} \mathrm{O}$ afetam a produção de MMSPA e, o excesso de $\mathrm{K}^{+}$induz inibição competitiva entre os cátions.

A fonte de $\mathrm{K}\left(\mathrm{K}_{2} \mathrm{SO}_{4}\right)$ é menos prejudicial quando em excesso em relação à fonte $\mathrm{KCl}$.

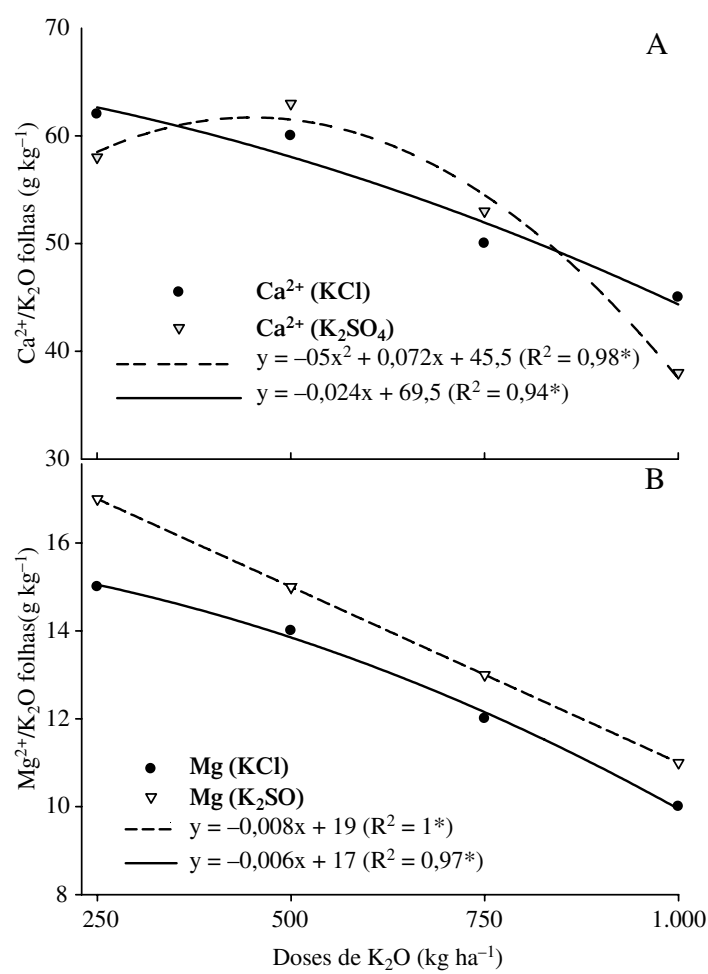

Figura 7. Relação média do teor de cálcio/potássio (Figura A) e magnésio/potássio (Figura B) em folhas de plantas de berinjela cultivadas em função de fontes de potássio $\left(\mathrm{KCl}\right.$ e $\left.\mathrm{K}_{2} \mathrm{SO}_{4}\right)$ e doses de potássio.

\section{Agradecimentos}

A Coordenação de Aperfeiçoamento Pessoal de Nível Superior (Capes) pela concessão da bolsa para obtenção do título de mestre do primeiro autor.

\section{Referências Citadas}

Aragão, C.A. et al.

2009 Avaliação de cultivares de melão sob condições de estresse salino. Revista Caatinga, Mossoró. 22 (2): 161169.

Azevedo Neto, A.D. et al.

2004 Effects salt stress on plant growth, stomatal response and solute accumulation of different maize genotypes. Brazilian Journal of Plant Physiology, Campinas. 16 (1): 31-38.

Asch, F.; Dingkuhn, M.; Dorffing, K.

2000 Salinity increases CO2 assimilation but reduces growth in field grown irrigated rice. Plant Soil. 218: 1-10.

Blanco, F.F.; Folegatti, M.V.; Nogueira, M.C.S.

2002 Fertirrigação com água salina e seus efeitos na produção do pepino enxertado cultivado em ambiente protegido. Horticultura Brasileira, Brasília. 20 (3): 442-446.
Bull, L.T.

1986 Influência da relação $\mathrm{K} /(\mathrm{Ca}+\mathrm{Mg})$ do solo na produção de matéria seca e na absorção de potássio por gramínea e leguminosa forrageiras. Piracicaba (Tese-Doutorado), Escola Superior de Agricultura “Luiz de Queiroz", Universidade de São Paulo. 107 p.

Cunha, A.R.; Martins, D.

2009 Classificação climática para os municípios de Botucatu e São Manoel, SP. Irriga, Botucatu. 14 (1): 1-11.

Empresa Brasileira de Pesquisa Agropecuária 1997 Manual de métodos de análise de solo. Rio de Janeiro: CNPS.

Epstein, E.

1975 Nutrição mineral das plantas: princípios e perspectivas. São Paulo: EDUSP, 341 p. 
Ferreira, D.F.

1999 Sistema de análise de variância (Sisvar). versão 4.6. Lavras: Universidade Federal de Lavras.

Grattans, S.R.; Grieve, C.M.

1993 Mineral nutrient acquisition and response by plants grown in saline environments. In: Pessarakli, M. (Ed). Plant and Crop Stress. Tucson: Marcel Dekker, pp. 203-226.

Hagin, J.; Tucker, B.

1982 Fertilization of dryland and irrigated soils. Advanced Series in Agricultural Sciences, Berlin: Springer-Verlag. 12: 188-198.

Knott, J. E.

1957 Handbook for vegetable growers. John Wiley \& Sons, London Chapman \& Hall, $238 \mathrm{p}$.

Kawasaki, T.; Akiba, T.; Moritsugu, M.

1983 Effects of high concentrations of sodium chloride and polyethylene glycol on the growth and ion absorption in plants: I. Water culture experiments in a greenhouse. Plant and Soil, Dordrecht. 75: 75-85.

Khasawneh, F.E

1971 Solution ion activity on plant growth. Soil Science Society of America Proceedings, 35 (3): 426-436.

Lutts, S.; Bouharmont, J.; Kinet, J.M.

1999 Physiological characterizations of salt-resistant rice (Oryza sativa L.) somaclone. Australian Journal Botanic, 47: 835-849.

Malavolta, E.; Vitti, G. C.; Oliveira, S.A.

1997 Avaliação do estado nutricional das plantas: princípios e aplicações. 2. ed. rev. atual. Piracicaba: POTAFÓS.

Malavolta E.

1987 Nutrição mineral das plantas. In: Curso de Atualização em Fertilidade do Solo. Campinas: Fundação Cargill. 33-101.
Malavolta, E.

1980 Elementos de nutrição mineral de plantas. São Paulo: Agronômica Ceres, 215 p.

Marques, D.J.; Broetto, F.; Silva, E.C.

2010 Efeito do estresse mineral induzido por fontes e doses de potássio na produção de raízes em plantas de berinjela (Solanum melongena L.). Revista Caatinga, Mossoró. 23 (3): 7-12.

Nogueira, F.D.; Silva, E.B.E.; Guimarães, P.T.G.

2001 Adubação potássica do cafeeiro: sulfato de potássio. Washington, DC: SOPIB. $81 \mathrm{p}$.

Oliveira, A.B. de; Hernandez, F.F.F.; Assis Junior, R.N. de. 2008 Pó de coco verde, uma alternativa de substrato na produção de mudas de berinjela. Revista Ciência Agronômica, Fortaleza. 39 (1): 39-44.

Raij, B. Van et al. (Ed.).

1996 Recomendações de adubação e calagem para o estado de São Paulo. Boletim Técnico Instituto Agronômico de Campinas, Campinas, n. 100.

Silva et al.

2001 Efeito do nitrogênio e potássio na nutrição do pimentão cultivado em ambiente protegido. Revista Brasileira de Ciência do Solo. 25 (4): 913-922.

Souza, N.K.R.; Júnior, J.P.A; Amorim, S.M.C.

2007 Efeito do estresse salino sobre a produção de fitomassa em Physalis angulata L. (Solanaceae). Revista. Acadêmica, Curitiba. 5 (4): 379-384.

Tisdale, S.L.; Nelson, W.L.; Beaton, J.D.

1985 Soil fertility and fertilizers. 4.ed. New York: MacMilan Publ., 754 p. 